\title{
Coastal Processes within a Coral Reef Lagoon System: Erakor Lagoon, Efate Island, Vanuatu
}

\author{
Gaëlle Faivre $^{\dagger^{*}}$, Guilherme Vieira da Silva ${ }^{\dagger}$, Jim Aimbie ${ }^{\ddagger}$, Daniel Ware ${ }^{\dagger}$, Rodger Tomlinson ${ }^{\dagger}$, Brendan Mackey $^{\S}$, and \\ Hong Zhang ${ }^{\dagger}$ \\ †riffith Centre for \\ Coastal Management \\ Griffith University, \\ Australia \\ Department of Water \\ Resources, Vanuatu \\ ${ }^{\S}$ Griffith Climate Change \\ Response Program \\ Griffith University, \\ Australia \\ ${ }^{\dagger}$ School of Engineering \\ and Built Environment \\ Griffith University, \\ Australia
}

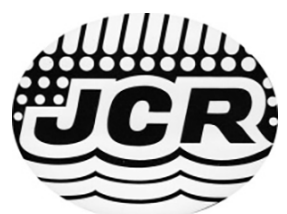

www.JCRonline.org

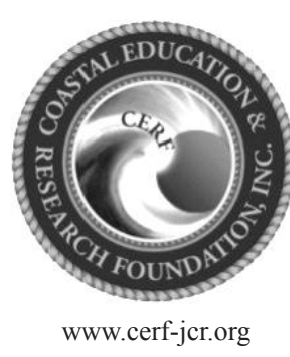

www.cerf-jer.org

\begin{abstract}
Faivre, G.; Vieira da Silva, G.; Aimbie, J.; Ware, D.; Tomlinson, R.; Mackey, B., and Hong, Z., 2020. Coastal processes within a coral reef lagoon system: Erakor lagoon, Efate Island, Vanuatu. In: Malvárez, G. and Navas, F. (eds.), Global Coastal Issues of 2020. Journal of Coastal Research, Special Issue No. 95, pp. 1427-1432. Coconut Creek (Florida), ISSN 0749-0208.

Small Island Developing States (SIDS) in the South Pacific are highly vulnerable to climate change and development pressure due to their small size, isolation and exposure to natural hazards. Much of the Pacific SIDS population reside within the coastal zone as does the majority of critical infrastructure where resilience is challenged by exposure to natural hazards including inundation and erosion, and impacts from cyclones and tsunamis,. During extreme events, wave energy is a significant damage vector whose impact on populations and infrastructure is mediated by the presence and structural characteristics of adjacent coral reefs. Understanding the role of the structural characteristics of reefs in the dissipation of wave energy is critical to planning climate change resilience for SIDS given climate change will alter water levels, waves climates and the condition of coral reefs. The aims of this paper are to understand (1) the wave dissipation over a coral reef and hydrodynamic circulation within a coral reef lagoon in Erakor lagoon, Port Vila the capital of Vanuatu, and (2) the impact of sea level rise on the wave energy, wave runup and impacts to the shoreline. The information from this assessment can help inform coastal adaptation planning in response to climate change and rising sea levels. The approach is based on using field data to calibrate a numerical model of coastal processes. A wave buoy and five pressure sensors were deployed to measure wave dissipation over the Erakor lagoon's reef and current meters used in the lagoon to measure circulation and residential time. Data processing shows the importance of the reef geomorphology and water levels on wave dissipation.
\end{abstract}

ADDITIONAL INDEX WORDS: Waves transformation, reef, climate change, hazards assessment, SIDS.

\section{INTRODUCTION}

Small Island Developing States in the South Pacific are highly vulnerable to coastal hazards, with Vanuatu ranked the world's most disaster-prone country by the World Risk Index (Garschagen et al. 2016). Coastal erosion, coastal flooding and coastal water quality are among the biggest concerns of SIDs in the South Pacific. Most of the Pacific islands are surrounded by a coral reef that serves as a natural protection to the coastline. Protecting coral reefs therefore is an ecosystem-based adaptation that could help protect assets and communities from coastal hazards. Understanding how much protection a coastal coral reef provides in a given situation however, is limited. Wave transformation across a reef is not fully understood due to the complexity of reefs and a lack of data collection.

This paper aims to better understand the role of fringing coral reefs in providing protection to a lagoon in Port Villa, the capital of Vanuatu. The data needed for calibrating fine resolution coastal

DOI: 10.2112/SI95-276.1 received 31 March 2019; accepted in revision 13 February 2020

*Corresponding author: g.faivre@griffith.edu.au

${ }^{\circ}$ Coastal Education and Research Foundation, Inc. 2020 process models are usually lacking in developing countries. Therefore, this study also aimed to test the utility in using rapid survey data for model calibration.

Gourlay (1994) demonstrated that the maximum depth-limited wave heights on a horizontal reef are less than those estimated in current engineering practice, which overestimates the wave energy reaching a structure. He showed that the maximum sizes of waves on reef flat are controlled by water depth and the maximum significant wavelength $\left(\mathrm{H}_{\mathrm{s}}\right)$ which is approximately 0.55 times the water depth (d), including any wave-generated set-up (Gourlay, 1994; Kench and Brander, 2006). More recent studies led by Killalea et al. (2017) has shown that the breaking index $\left(\Upsilon=\mathrm{H}_{\mathrm{s}} / \mathrm{d}\right)$ could be improved for fringing reef locations where rapid bathymetric transitions occur across the reef edge. Given this, the impacts of the reef complexity for wave dissipation are highlighted here.

\section{METHODS}

\section{Case Study Location}

Efate Island is the most populous island in Vanuatu with most inhabitants located in Port Vila. Hydrodynamic processes were modelled within the Erakor lagoon system. Erakor lagoon is 


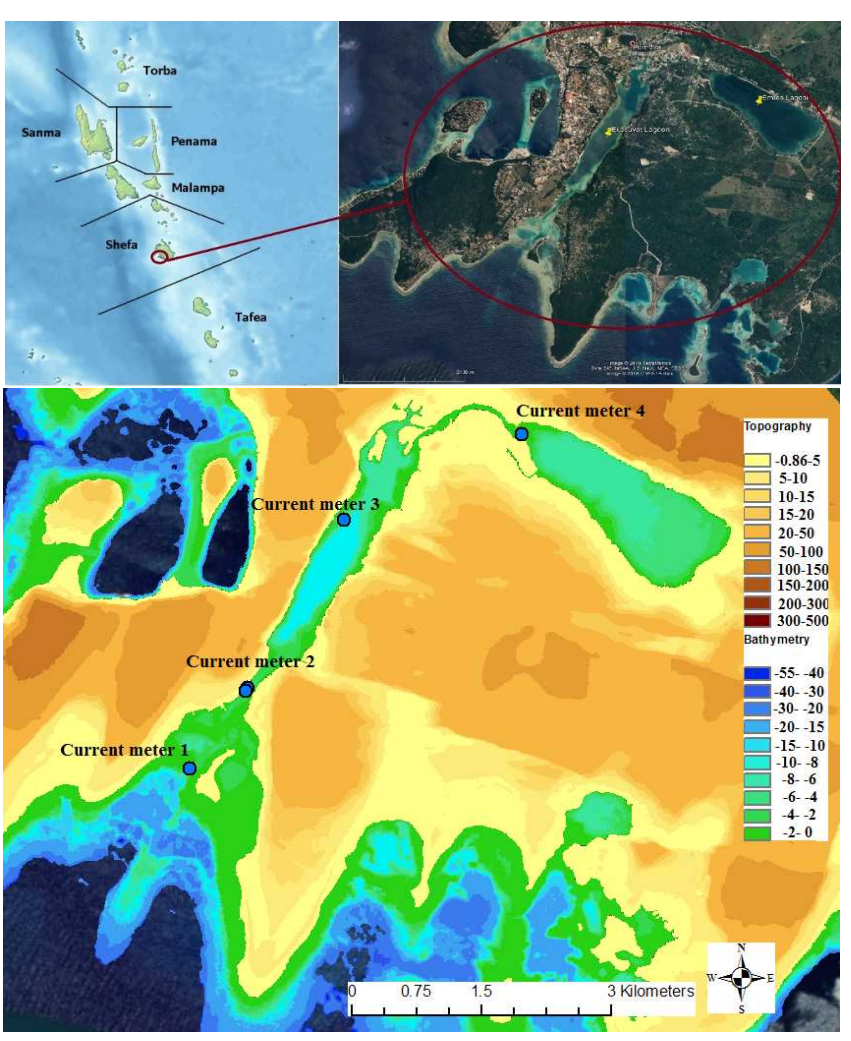

Figure 1. Erakor lagoon systems consisting of two lagoons: Ekasuvat and Emten lagoons located in Efate island, Vanuatu.

located on the East side of the Island's capital Port Vila. Erakor lagoon consists of two sub-lagoons Ekasuvat Lagoon and Emten Lagoon as shown in Figure 1. Ekasuvat Lagoon is around $3 \mathrm{~km}$ long and $500 \mathrm{~m}$ wide, around $10.7 \mathrm{~m}$ deep and has an entrance to the ocean at the southern end and a second outlet that leads to Emten Lagoon which is around $2.5 \mathrm{~km}$ long, $750 \mathrm{~m}$ wide and around $6.4 \mathrm{~m}$ deep (Carter, 1983). A channel of around $1 \mathrm{~km}$ long and $60 \mathrm{~m}$ wide links the two lagoons. Ekasuvat lagoon is linked to the ocean by a $750 \mathrm{~m}$ long channel and around $100 \mathrm{~m}$ wide with water depths ranging from $2.5 \mathrm{~m}$ to $4 \mathrm{~m}$ at the entrance of the lagoon. Erakor Lagoon is connected to the ocean by a flat reef (from $500 \mathrm{~m}$ to $800 \mathrm{~m}$ wide), reef crest and forereef (from $60 \mathrm{~m}$ to $200 \mathrm{~m}$ wide). The reef flat is a complex and shallow system with water depth varying from $2 \mathrm{~m}$ to $0.5 \mathrm{~m}$ and is covered by various reef organisms. Erakor island is located at the entrance of Erakor lagoon and surrounded by a reef flat. Large parts of the reef flat are aerially exposed during low tides. Erakor Island is only habited by a resort and its highest point is around $5 \mathrm{~m}$ above mean sea level (Data Vanuatu government, 2012) which makes the island very vulnerable to coastal flooding during extreme events. A very highresolution LiDAR survey for Erakor lagoon from a partnership between the Government of Australia and the Government of Vanuatu provides a bathymetric and topographic data with $5 \mathrm{~m}$ resolution and $1 \mathrm{~m}$ resolution respectively. The majority of studies of coastal hazard assessment use numerical models calibrated with local wave buoys and pressure gauges.

A SEAFRAME (Sea Level Fine Resolution Acoustic Measuring Equipment) tide gauge has been installed in Port Vila (lon: 168.307694'; lat: $17.755334^{\circ}$ ) since March 1993 as a part of the

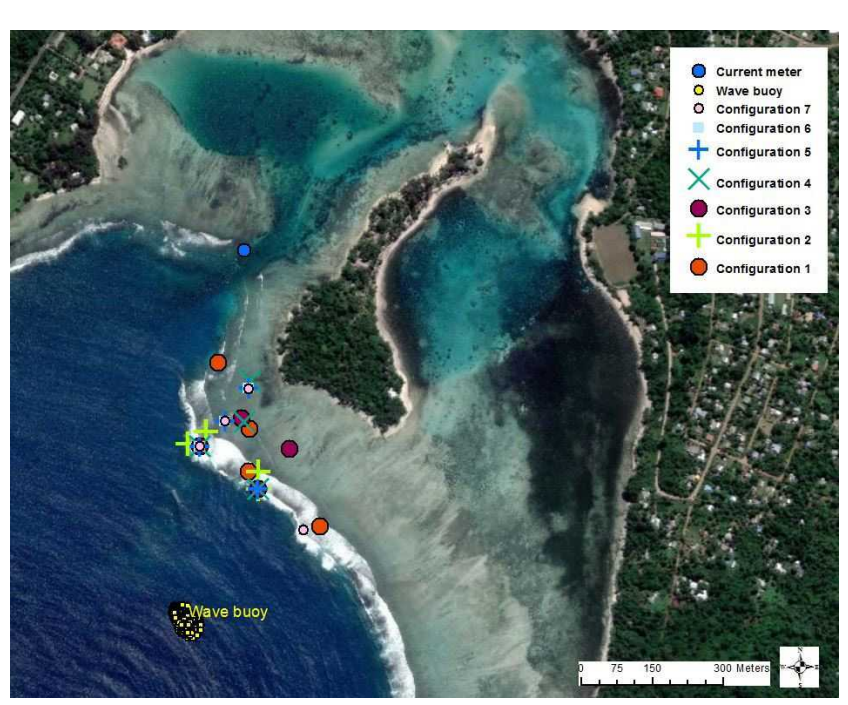

Figure 2. Location of instruments within Erakor.

South Pacific Sea Level Monitoring Project (PSLMP) (SPREP, 2006). Erakor lagoon experiences semidiurnal micro tidal regime with a range of $\sim 1.5 \mathrm{~m}$. Erakor lagoon is exposed to south-east swell (Faivre et al., 2019) and South East tradewinds blow from May to October (Bosserelle et al., 2015).

\section{Data Collection}

Data were collected in May 2019. Waves outside the reef were measured with a spoondrift spotter (Spoondrift, 2019) with a mooring deployed at $\sim 30 \mathrm{~m}$ deep. The mooring consisted of a weight of around $50 \mathrm{~kg}$, two surface buoys to buffer against biofouling and to isolate the spotter from any dampening effects of having growth on the line, and a subsurface float for maintaining the subsurface section of line vertical. Measurements were available remotely through the online Dashboard. Significant wave height, wave direction and peak wave period were measured from 07/05/2019 11:48:46 to 30/05/2019 04:24:18. The spoondrift is also equipped by a GPS allowing to spot its position.

Five high-frequency pressure transducers (Wave and tide RBR duet T.D compact instruments) were deployed to measure waves and water level on the reef crest and over the reef flat in front of Erakor Island. In this study, data have been collected in seven configurations (Figure 2) to compare variation of the waves with depth and observe cross-shore and alongshore variations. Wave characteristics and wave spectra were analysed in each configuration.

The pressure transducers were fixed to the reef at low tide to avoid the rough waves conditions that occurs during high tide. The sensors were pre-calibrated by the manufacturer. The sampling rate was recorded continuously at $4 \mathrm{~Hz}$ allowing for analysis of short and infragravity waves and water levels. The data was logged into Ruskin software and then processed in Matlab R2017a using Tucker and Pitt (2001) wave calculation methods.

The measured pressures were corrected by the atmospheric pressure collected by SEAFRAME gauge. To avoid overamplifying noise from high-frequency variations, the attenuation of pressure variations with depth was corrected over the range 0.05-0.33 and the tide was removed from the signal. The significant wave heights and the peak wave periods were calculated from 
Table 1. Depth of RBR for all configuration.

\begin{tabular}{|c|c|c|c|}
\hline Periods & Configuration & Instrument & Depth \\
\hline \multirow[t]{4}{*}{ 08/05 16:00-11/05 09:00 } & 1 & RBR67 & $2.0721 \mathrm{~m}$ \\
\hline & 1 & RBR64 & $0.6540 \mathrm{~m}$ \\
\hline & 1 & RBR65 & $0.7105 \mathrm{~m}$ \\
\hline & 1 & RBR62 & $1.0745 \mathrm{~m}$ \\
\hline \multirow[t]{4}{*}{ 11/05 15:00-14/05 08:20 } & 2 & RBR67 & $2.0800 \mathrm{~m}$ \\
\hline & 2 & RBR64 & $0.5592 \mathrm{~m}$ \\
\hline & 2 & RBR65 & $0.7686 \mathrm{~m}$ \\
\hline & 2 & RBR62 & $1.9060 \mathrm{~m}$ \\
\hline \multirow[t]{4}{*}{ 14/05 12:00-21/05 11:30 } & 3 & RBR67 & $2.5713 \mathrm{~m}$ \\
\hline & 3 & RBR64 & $0.3952 \mathrm{~m}$ \\
\hline & 3 & RBR65 & $0.6547 \mathrm{~m}$ \\
\hline & 3 & RBR62 & $2.3254 \mathrm{~m}$ \\
\hline \multirow[t]{4}{*}{$21 / 05$ 16:00-23/05 13:00 } & 4 & RBR67 & $2.5713 \mathrm{~m}$ \\
\hline & 4 & RBR64 & $0.7165 \mathrm{~m}$ \\
\hline & 4 & RBR65 & $0.5276 \mathrm{~m}$ \\
\hline & 4 & RBR62 & $2.3254 \mathrm{~m}$ \\
\hline \multirow[t]{4}{*}{$23 / 05$ 16:00-25/05 08:20 } & 5 & RBR67 & $2.5713 \mathrm{~m}$ \\
\hline & 5 & RBR64 & $0.6840 \mathrm{~m}$ \\
\hline & 5 & RBR65 & $0.4722 \mathrm{~m}$ \\
\hline & 5 & RBR62 & $2.3254 \mathrm{~m}$ \\
\hline \multirow[t]{4}{*}{$25 / 05$ 11:00-27/05 07:00 } & 6 & RBR67 & $2.4652 \mathrm{~m}$ \\
\hline & 6 & RBR64 & $0.6845 \mathrm{~m}$ \\
\hline & 6 & RBR65 & $0.4632 \mathrm{~m}$ \\
\hline & 6 & RBR62 & $2.3254 \mathrm{~m}$ \\
\hline \multirow[t]{4}{*}{ 25/05 11:00-30/05 08:00 } & 7 & RBR67 & $0.9787 \mathrm{~m}$ \\
\hline & 7 & RBR64 & $0.6560 \mathrm{~m}$ \\
\hline & 7 & RBR65 & $0.4632 \mathrm{~m}$ \\
\hline & 7 & RBR62 & $2.3254 \mathrm{~m}$ \\
\hline
\end{tabular}

the wave spectra. The analysis of the distribution of wave energy is deduced from a spectral analysis. Wave parameters and wave energy distribution were compared for each site to estimates the wave dissipation over the reef. Longshore and cross shore variations are both compared.

In this study, short waves and infragravity waves were considered using wave spectrum frequencies of $0.05-0.4 \mathrm{~Hz}$ for the short waves and less than $0.05 \mathrm{~Hz}$ for the infragravity waves. The total water depths where the sensors were deployed are used to estimate the range of wave frequencies and periods that can be resolved. These values are shown in Table 1.

Currents measurement were made using Marotte HS drag tilt current meter. These instruments were installed at the bottom of the sea bed and fixed to a block of concrete (Figure 3) where they

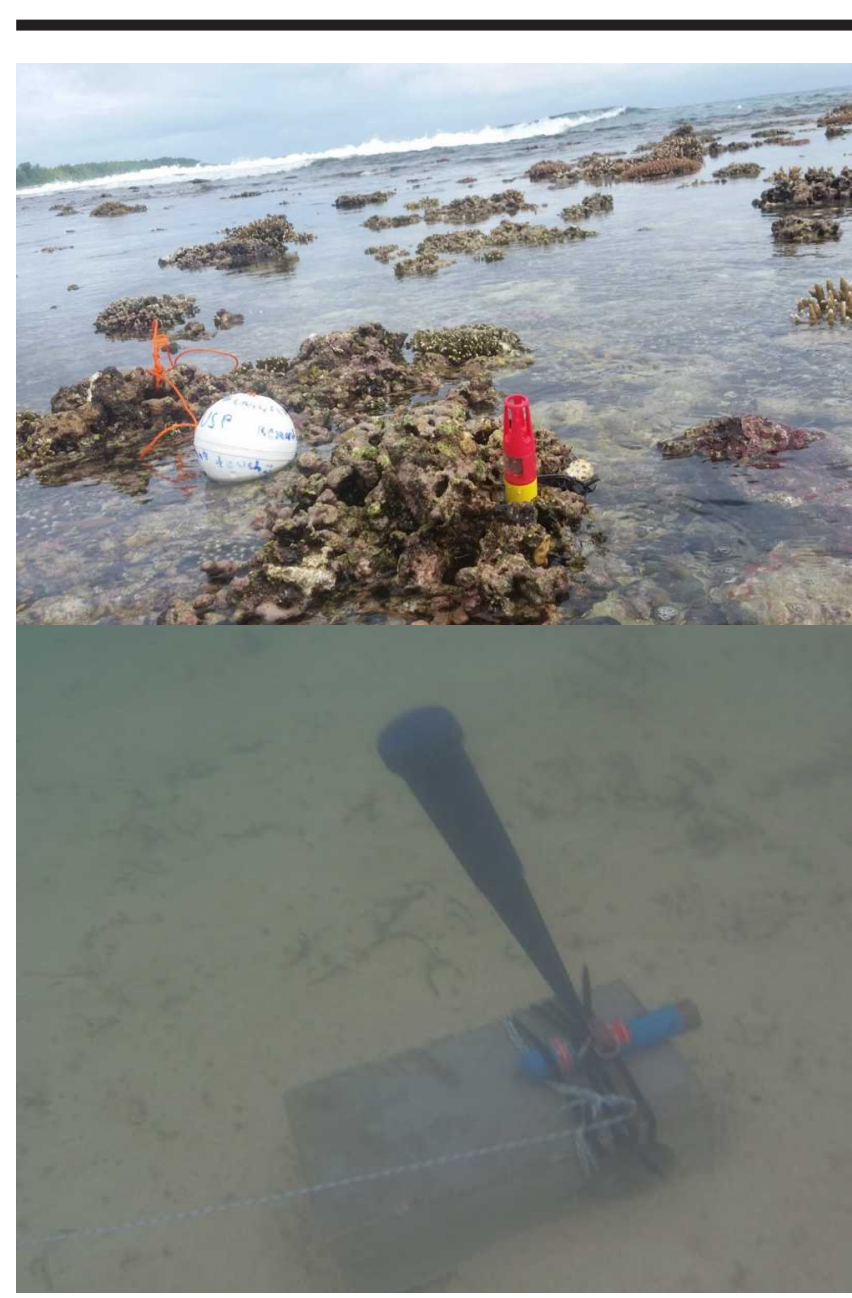

Figure 3. Example RBR monitoring station over the flat reef showing the aerial exposition during low tide (left) and example of current monitoring station (right).

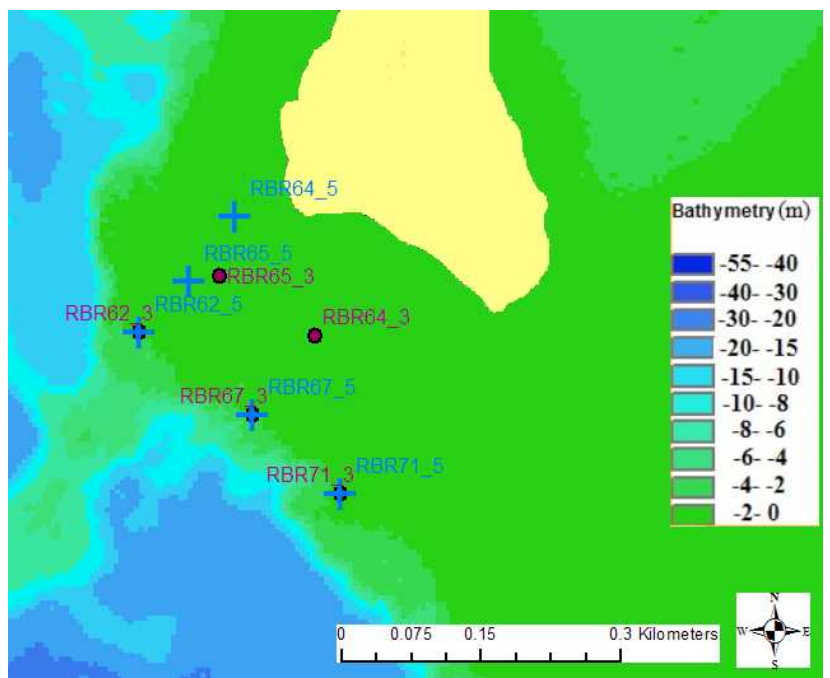

Figure 4. Location of pressure sensors over the reef during deployment 3 (red) and deployment 5 (blue). 
measure current velocity at a fixed point in the water column. The buoyancy force causes the instrument to float directly upwards when there is no current (JCU Marine Geophysics Laboratory, 2019).

These data will be used to calibrate numerical model of the lagoon and to inform circulation in the lagoon. All the instruments were easily visible from the surface due to a small white float at each monitoring station. The wave attenuation was compared as a function of the depth in each configuration. These configurations were chosen for a better understanding of the reef as a function of its width, allowing understanding both alongshore, and crosshore transformations. Sometimes, instruments were replaced due to missing instruments. RBR71 is not considered in Table 1 as it has been deficient. RBR62, 67 and 71 were deployed in a straight line in the lee of the reef crest.

During low tide, some pressure sensors were exposed particularly during the spring tide in mid-May 2019. Some irregularities or noise have been cut off from the signal due to the movement of the instrument. In most cases, it was either for relocation or the instrument were moved by local inhabitants.

\section{RESULTS}

\section{Wave Analysis of Erakor Lagoon}

As waves propagate from deep water to the reef slope, variations in the significant wave heights are observed due to shoaling and dissipation cause by wave breaking and bottom friction (Massel, 1992). As a result, each deployment was analysed and compared per location and depth. In this paper, results are shown for configurations 3 and 5 allowing the identification of cross-shore and alongshore variations (Figure 4).

The slope of the forereef, seaward of the reef crest is spatially variable for the along reef RBR array. RBR 62, RBR 67 and RBR 71 were all situated in the lee of a gentle slope that becomes abrupt $\left(\sim 30^{\circ}\right)$. The length of the steep slope varies alongshore. The forereef steep slope of RBR 71 extends on a longer distance than RBR 67. RBR 62 was situated in the lee of the most gentle forereef gradient $\left(\sim 2^{\circ}\right)$. However, at the East-South-East, RBR 62 has the steepest gradient. In other words, the forereef in front of RBR 62 extends on a longer distance $(\sim 340 \mathrm{~m})$ than the RBR 67 (25m) and RBR 71 slopes $(25 \mathrm{~m})$.

Figure 5 shows the significant wave height at reef crests, over the reef flat and highlights the influence of the tide.

The significant wave heights are modulated by the tide over the reef flat. There is a direct correlation between the tide and the wave heights; the waves increase at high tide and decrease at low tide. In addition, the results show the impact of the reef crest width on the significant wave height. While RBR 62 and 67 are both at the reef crest at $2.3 \mathrm{~m}$ and $2.5 \mathrm{~m}$ depth respectively, the significant wave high at RBR 62 is amplified by $30 \%$ compared to the significant wave height at RBR 67. RBR 62 is at the top of a wide reef crest, at around $325 \mathrm{~m}$ from the steep fore reef slope. RBR 67 has a narrow reef crest, it is only at $40 \mathrm{~m}$ from the steep fore reef slope. Reefs significantly reduce wave height. The significant wave height at RBR 65 has been reduced by 34\% and at RBR 64 by $80 \%$ for deployment 3 . However the increase of dissipation at RBR 64 is likely to be associated with the bathymetry. According to deployment 5, the wave at the reef crest (RBR 62) has been reduced by $21 \%$ at RBR 65 and by $22 \%$ at RBR 64 . Regarding along shore variations, the reef width amplifies wave height at RBR 62 by $27 \%$ in comparison with wave height of RBR 67 . This

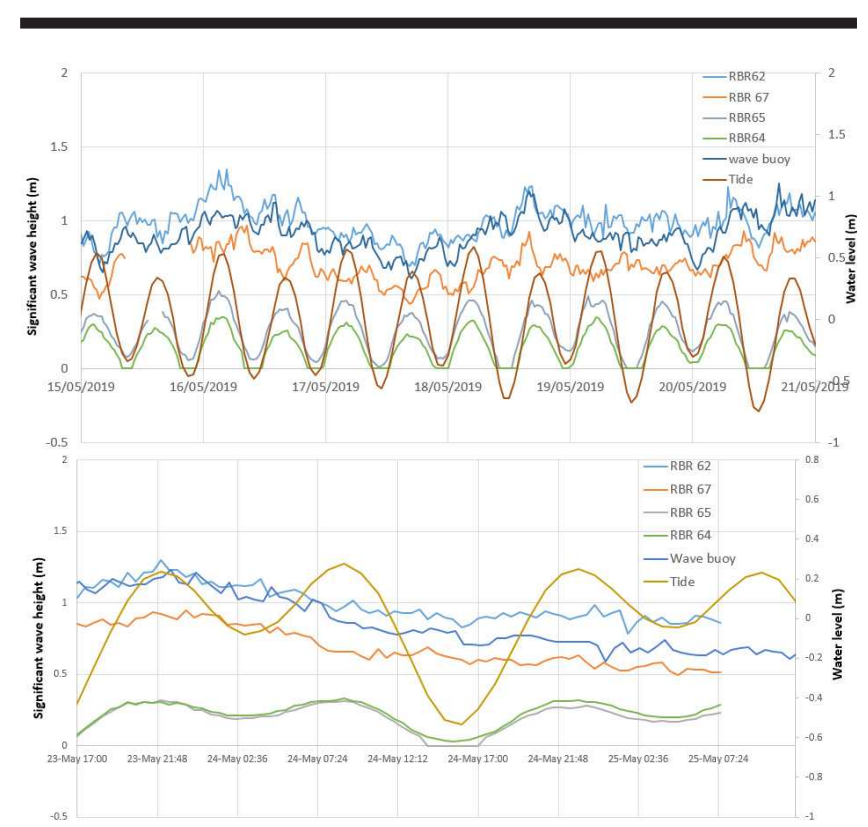

Figure 5. Tide and significant wave height at the reef crest, over the flat reef and outside the reef during deployment 3 (top) and during deployment 5 (bottom).

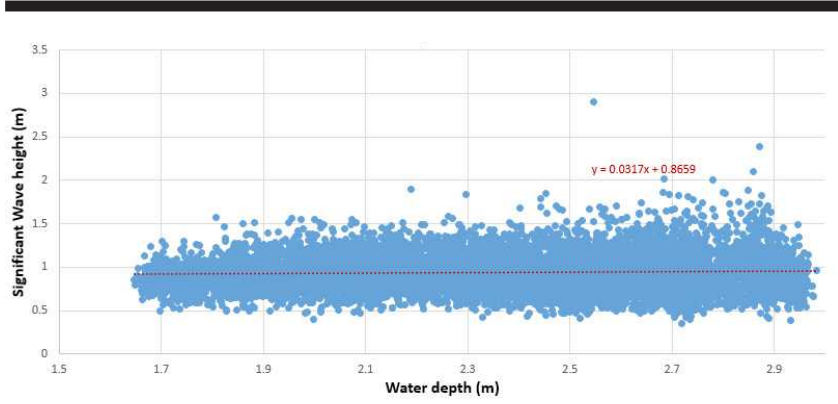

Figure 6. Relationship between significant wave heights and local water depth at the reef crest (RBR62) during deployment 3.

result is quite consistent with the previous deployment. It is also noticed that the significant wave height at the wave buoy has been slightly amplified by $23 \%$ at RBR 62 during the configuration 5 . This is likely due to the wave direction and slope of the reef.

The wave energy at the reef crest (RBR62) is amplified by $55 \%$ comparing with RBR 67 during deployment 3 and deployment 5. The wave energy at RBR 65 has been reduced by $70 \%$ during deployment 3 and by $88 \%$ during deployment 5 .

Figure 6 shows the relationship between significant wave heights and local water depth at the reef crest (RBR62) during deployment 3. An average ratio of 0.41 has been found for the wave height on the local water depth at the reef crest (RBR62).

\section{Currents Monitoring Results}

Current speed and current direction were monitored from $06 / 05 / 2019$ to $30 / 05 / 2019$ at four locations as shown in Figure 1. The current has been correlated with the tide (Figure 7). At low tide, the faster currents are observed and reaching speeds of around $0.6 \mathrm{~m} / \mathrm{s}$ at the lagoon entrance (current meter 1) and $\sim 0.4$ $\mathrm{m} / \mathrm{s}$ in the channel connecting Erakor lagoon to Ekasuvat lagoon 


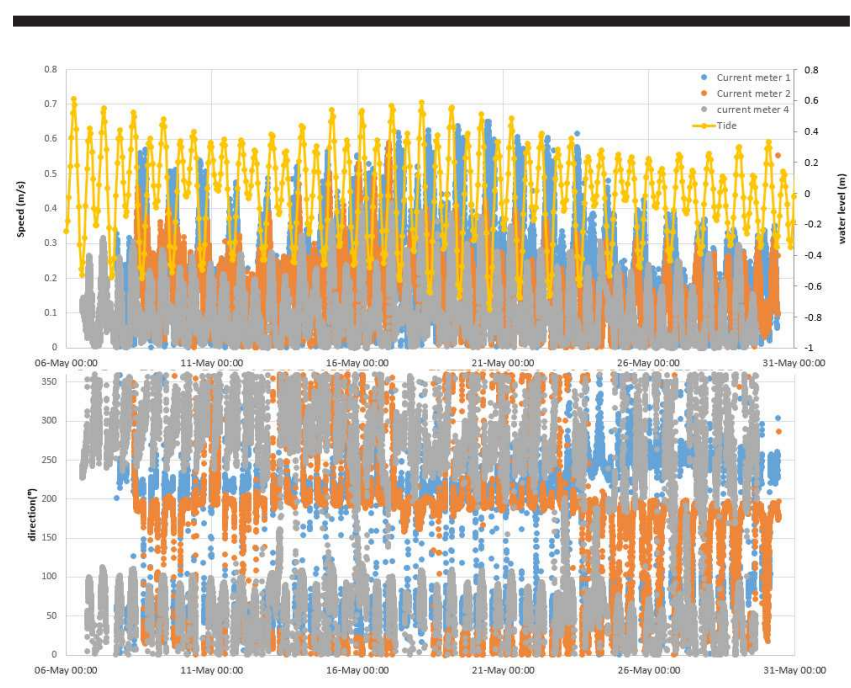

Figure 7. Current Speed and current direction as a function of the tide for current meter 1 , current meter 2 and current meter 4 .

(current meter 2) and in the channel connecting Ekasuvat and Emtem lagoon (current meter 4). At the upcoming tide, the current speed decreases $(\sim 0.2 \mathrm{~m} / \mathrm{s})$ and it is minimal at the highest tide. In addition, the tide is variable within the lagoon. At the upstream, the lowest tide is reached around an hour later of the lowest tide at the entrance of the lagoon. The entrance of the lagoon (current meter 1) has the strongest current due to a narrow channel between separating the reef flat. Its direction varies between $\sim 210^{\circ}$ and $30^{\circ}$ depending on the tide.

\section{DISCUSSION}

The results show that the complexity of the reef combined to the water level really influence the significant wave height and wave energy. Coral reefs dissipate the wave energy through a range of factors like the bottom roughness and the bed shear stress. The significant wave height is highly influenced by the tide over the reef flat. Consequently, future projections of increasing water levels are likely to change wave transformation and dissipation over the reef. If sea level rise is faster than the ability of the reef to grow and maintain its depth, the coastline behind the reef may be significantly impacted by larger waves.

Cross-shore and alongshore wave variations were shown to be highly dependent on reef geomorphologies. The width of the reef crest to the bottom of the fore reef and the slope of the fore reef amplify significantly wave heights and then wave energy. The wave height is generally reduced by $80 \%$ over the reef flat. The longshore reef variabilities studies are really important to be considered and are often omitted. The results show that the wave could be amplified by $27 \%$ at the reef crest due to the slope and reef width. This result needs to be taken in account for building artificial reef structures for effectiveness of risks reductions or surf quality for example.

The entrance of the lagoon should be flushed in a tidal cycle due to the strong current. However, some concerns in the flushing time of lagoon 2 appear due to lower currents and higher distance to the ocean. Based on the dimension of the lagoon and current, it appears that more than a full tidal cycle is needed to flushed the lagoon 2 entirely.

\section{CONCLUSIONS}

A rapid survey where data were collected over a one-month period proved sufficient to calibrate an initial model of coastal and within-lagoon hydrodynamic processes providing insight into the role of the coral reef on wave dynamics.

Until this study, only global wave data were available to study coastal processes within Erakor lagoon. A wave buoy has been installed outside the reef to calibrate a numerical model for the future. Ongoing research will aim to verify the breaking wave index considering the width of the reef. These measurements will allow better calibration of the model and establishing scenarios for coastal risk assessments. The location of the reef and wave characteristics created are important to be considered for coastal risk assessment and for water quality purposes particularly with development occurring around the lagoon. The current within the lagoon is highly dependent on the tide, which needs to be considered for water management particularly for discharge studies.

\section{ACKNOWLEDGMENTS}

The authors are grateful to the Department of Water Resources of Vanuatu, the Office of the Maritime Regulator, and the University of South Pacific for supporting data collection in this study. Data collection was enabled by the support and involvement of the local communities and customary owners of the lagoons and associated land. In addition to assisting with the data collection, we are also grateful for the assistance in protecting the instruments during the survey period. This research was supported by a grant from a private charitable trust and under the approval of the research agreement between the cultural council and Griffith University.

\section{LITERATURE CITED}

Bosserelle, C.; Reddy, S., and Lal, D., 2015. WACOP wave climate reports. Efate nearshore wave hindcast, Breakas Beach. Secretariat of the Pacific Community. Available at http://gsd.spc.int/wacop/.

Carter, R., 1983. Baseline studies of Port Vila and Erakor Lagoons, Vanuatu. Cruise VA-83-1.Cruise Report No.82.

Faivre, G.; Viera da Silva, G.; Ware, D.; Tomlinson, R.; Mackey, B., and Zhang, H., 2019. Wave climate in Port Vila, Efate and effects to the shoreline. Australasian Coasts \& Ports 2019 Conference - Hobart, 10-13 September 2019.

Garschagen, M.; Hagenlocher, M.; Comes, M.; Dubbert, M.; Sabelfeld, R.; Lee, Y.J.; Grunewald, L.; Lanzendörfer, M.; Mucke, P.; Neuschäfer, O.; Pott, S.; Post, J.; Schramm, S.; Schumann-Bölsche, D.; Vandemeulebroecke, B.; Welle, T., and Birkmann, J., 2016. World Risk Report 2016. World Risk Report. Bündnis Entwicklung Hilft and UNU-EHS.

Gourlay, M.R., 1994. Wave transformation on a coral reef. Coastal Engineering, 23, 17-42.

JCU Marine Geophysics Laboratory, 2019. Marotte HS User Guide, Version 2.0.

Kench, P.S., and Brander, R.W., 2006. Response of reef island shorelines to seasonal climate oscillations: South Maalhosmadulu atoll, Maldives, Journal of Geophysical Research, 111, F01001, doi: 10.1029/2005JF000323.

Killalea, R.; Splinter; K.D.; Blacka, M., and Barthelemy, X., 2017. Considerations for the design of rock armoured structures on fringing reef coastlines [online]. Australasian Coasts and Ports 2017: Working with Nature. Barton, ACT: Engineers 
Australia, PIANC Australia and Institute of Professional Engineers New Zealand, 697-703.

Massel, S., 1992. Wave transformation and dissipation on steep reef slopes. $11^{\text {th }}$ Australasian Fluid Mechanics Conference, University of Tasmania, Hobart, Australia, 14-18 December 1992.
SPREP, 2006. Sea Level and Climate. Pacific Country Report, Vanuatu.

Tucker, M.J. and Pitt E.G., 01 Waves in ocean engineering. Elsevier ocean engineering book series vol. 5, Elsevier, Amsterdam, $521 \mathrm{p}$. 